\title{
Críticas à teoria da escolha racional e hierarquias de conhecimento na ciência política
}

\author{
Enzo Lenine Nunes Batista Oliveira Lima ${ }^{1}$
}

Durante o seu desenvolvimento nos séculos XX e XXI, a teoria da escolha racional (doravante, TER) foi bombardeada por críticas vindas de todas as direçóes. Previsôes triviais, pressupostos irrealistas, modelagem simplista são apenas algumas das palavras-chave usadas pelos críticos da teoria e de sua metodologia matemática. Considerando a natureza transversal da abordagem da escolha racional, as críticas surgiram em uma miríade de disciplinas, como a psicologia, a economia, a sociologia e, evidentemente, a própria ciência política. Em nossa disciplina, a crítica mais aclamada foi apresentada por Donald Green e Ian Shapiro (1994), em seu Pathologies of rational choice theory; nas ciências comportamentais, Daniel Kahneman e Amos Tversky (2000) conduziram sistemática e consistentemente experimentos e desenvolveram teorias para explicar as complexidades da mente humana frequentemente ignoradas pela TER. Além disso, os teóricos da escolha racional (DOWDING, 2005; DOWDING; HINDMOOR, 1997; FIORINA, 1995; LOHMANN, 1995) também têm sua contribuição para esse debate, fornecendo críticas sobre a abordagem e sua metodologia.

Embora algumas críticas compartilhem características comuns, as bases teóricas e empíricas nas quais são fundamentadas são substancialmente diferentes. Para entender o seu conteúdo, neste artigo divido-as em duas classes: críticas teóricas e empíricas. A primeira engloba problemas comportamentais e cognitivos que estão ausentes em modelos matemáticos de escolha racional. Herbert A. Simon (1957) foi, talvez, o primeiro a considerar sistematicamente os limites da suposição de racionalidade, propondo um modelo baseado na racionalidade limitada. Kahneman e Tversky (2000), bem como Gerd Gigerenzer e Reinhard Selten (2001), desenvolveram estudos e metodologias para explicar os aspectos cognitivos do comportamento humano. Essa vasta literatura forneceu insights valiosos e críticas à TER, apesar dos limites de sua implementação em modelos matemáticos. Além dessas críticas, a modelagem simplista encontra-se no centro das discussóes, especialmente no que tange aos pressupostos de maximização de utilidade. Geoffrey Hodgson (2012) é um crítico feroz da validade de tais conceitos, alegando que eles não são observáveis nem mensuráveis.

As críticas empíricas concentram-se principalmente na falta de sucesso da TER quando esta e seus modelos são confrontados com casos reais. A crítica de Green e Shapiro (1994), especificamente, baseia-se em uma série de previsóes não realizadas de casos específicos. Seu livro ainda é a crítica mais sistemática e abrangente da TER na disciplina, portanto dedico uma

1 Doutor e mestre em Ciência Política pela Universidade Federal do Rio Grande do Sul (UFRGS). Sua pesquisa atual enquadra-se nas áreas de hierarquias de conhecimento e modelagem matemática, preocupando-se com questôes epistemológicas e metodológicas da Ciência Política contemporânea, especialmente teoria institucional, teoria da escolha racional, modelagem matemática e teoria normativa. E-mail: leninelima@gmail.com 
seção inteira para examinar seus argumentos e as reaçóes contra eles. O debate que se desenrolou desde então é profundamente esclarecedor em termos do que a abordagem da escolha racional significa e como ela gera previsóes. Em termos gerais, essa linha de críticas ignora que os modelos matemáticos de escolha racional produzem explicaçóes sobre fenômenos gerais, náo casos particulares - como, por exemplo, por que Valentina decide se apresentar à comissáo eleitoral em um domingo chuvoso e votar.

Mais recentemente, os debates sobre a TER também se concentraram nas hierarquias do conhecimento em ciência política. Havia um sentimento na disciplina de que os teóricos da escolha racional tinham um plano hegemônico de dominação teórica e metodológica ${ }^{2}$, que parecia ser confirmado pelo aumento da presença de artigos orientados para a escolha racional na American Political Science Review (APSR) (BECKER, 1976; COX, 1999). Não é de admirar por que o Movimento Perestroika, entre outras coisas, criticou a orientação à teoria dos jogos na APSR e, em larga medida, secundada pela American Political Science Association (APSA). Por mais difícil que seja declarar como resultado da Perestroika, nos anos 2000 a quantidade de artigos que exibem algum tipo de modelo formal ou abordagem racional-dedutiva diminuiu drasticamente nas revistas americanas mais prestigiadas (ISHIYAMA, 2015; JACOBY et al., 2017). Uma nova era de artigos quantitativos - e, até certo ponto, trabalhos qualitativos - contribuiu para a diminuição da quantidade de envios com base em modelos formais, favorecendo-os principalmente quando são acompanhados de testes empíricos.
Nesse contexto, este artigo objetiva apresentar as principais críticas à TER e à modelagem formal. A primeira seção discute as críticas formuladas pela literatura sobre psicologia cognitiva. Segue-se então a crítica empírica na ciência política, principalmente por meio da obra de Green e Shapiro (1994) e as reaçóes a ela e a outras críticas. A última seção discute o estado atual da TER em termos de hierarquias de conhecimento na disciplina, oferecendo um panorama da TER e dos modelos formais em três periódicos de prestígio na ciência política.

\section{Críticas teóricas}

Talvez as acusaçóes mais graves e importantes contra a TER possuam uma base teórica. Uma crítica tradicional que reverbera em muitas disciplinas questiona a validade da suposição de racionalidade e sua conexão com a maximização da utilidade. A história por trás do comportamento racional frequentemente ignora outros elementos por motivos de modelagem, como normas, referências culturais, valores morais, altruísmo e deliberaçóes, apenas para citar alguns (HINDMOOR; TAYLOR, 2015; SEN, 1994, 1997, 2009). Nesse contexto, a teoria da utilidade esperada (Expected Utility - EU), que é um modelo de comportamento de tomada de decisão sob incerteza, é um dos principais objetivos da crítica. A EU foi sistematicamente desenvolvida por John von Neumann e Oskar Morgenstern (2007) como parte de sua teoria de decisão e logo se tornou amplamente utilizada em economia e ciência política. Ela assume quatro axiomas (completude ${ }^{3}$,

2 Gary Becker, eminente economista e laureado com o Nobel de Economia de 1992, defendeu o amplo uso da TER em diversas áreas da vida social e econômica. Sua obra tratou de temas como discriminação racial, criminalidade, drogas, entre outros.

3 Completude: todas as alternativas em um dado conjunto de alternativas são comparáveis entre si. Em outras palavras, ai pode ser preferível a aj; aj pode ser preferível a ai; ou o indivíduo pode ser indiferente entre elas. 
transitividade $e^{4}$, independência de alternativas irrelevantes ${ }^{5}$ e continuidade ${ }^{6}$ ), que produzem a famosa equação representada pela Equação 1, na qual $c i$ representa o resultado $i$; $p i$ a probabilidade correspondente; e $L$ uma loteria.

$$
\begin{gathered}
\text { Equaçáo 1 } \\
\begin{aligned}
E U(L)=u(c 1) p 1 & +u(c 2) p 2+\ldots+u(c n) p n \\
& =\sum \mathrm{u} i p i
\end{aligned}
\end{gathered}
$$

As críticas contra a EU especificamente, $\mathrm{e}$ a TER mais amplamente, são frequentemente baseadas nas descobertas e argumentos de outras disciplinas, especialmente psicologia e filosofia, respectivamente. Na psicologia, a suposição de que os indivíduos se comportam de forma racional tem sido contestada desde o modelo de racionalidade limitada de Simon (1957), que foi seguido por uma miríade de experimentos, muitos deles conduzidos com base nas teorias de Kahneman e Tversky (2000). Na filosofia, especialmente no domínio da filosofia da ciência, o debate orbitou em torno das capacidades explicativas e representativas dos modelos (LIMA, 2018).

Simon escreveu uma série de artigos sobre a questáo da racionalidade. Sua abordagem da questâo foi posteriormente reconhecida como racionalidade limitada, sendo frequentemente citada nas obras de Kahneman, Gigerenzer e Amartya Sen. A pesquisa de Simon está localizada nas interfaces de diferentes disciplinas, nomeadamente economia, ciência política, psicologia cognitiva e ciências comportamentais. $\mathrm{O}$ autor tenta fornecer uma interpretação alternativa do Homo economicus, favorecendo uma abordagem mais realista de suas habilidades de "computar" preferências, estratégias e resultados. De acordo com sua proposição teórica, um modelo comportamental deve capturar as limitaçóes cognitivas da mente humana e os efeitos externos derivados do meio ambiente. A base do argumento de Simon (1957) é que os agentes não possuem os atributos da racionalidade perfeita, mas são bastante limitados pelo que ele define como racionalidade limitada. Em suas palavras (Ibidem, p. 252, tradução minha):

\begin{abstract}
$\mathrm{Na}$ maioria dos modelos globais de escolha racional, todas as alternativas são avaliadas antes de uma escolha ser feita. Na tomada de decisão real, as alternativas são frequentemente examinadas sequencialmente. Podemos ou náo saber o mecanismo que determina a ordem do procedimento. Quando as alternativas são examinadas sequencialmente, podemos considerar a primeira alternativa satisfatória que é avaliada tal como a que realmente foi selecionada ${ }^{7}$.
\end{abstract}

A essência do modelo de Simon reside na alternativa satisfatória, id est, no conceito de satisfação: agentes, ao analisarem a estrutura do meio ambiente/contexto, tomam decisóes que visam a satisfazer em vez de maximizar a utilidade. Simon descreve o ambiente em termos das necessidades, desejos e objetivos de um agente. Os agentes possuem uma variedade de objetivos, mas apenas um é importante para um determinado processo decisório. Como a percepção de um agente sobre o meio ambiente é limitada, ele não pode tentar maximizar

4 Transitividade: se A é preferível a B, e B é preferível a C; então, necessariamente, A é preferível a C.

5 Independência de alternativas irrelevantes: a preferência social entre ai e aj depende somente da preferência individual por ai e aj. A introdução de ak não deve interferir no ordenamento de preferência de ai e aj.

6 Continuidade: a função de utilidade é contínua.

7 "In most global models of rational choice, all alternatives are evaluated before a choice is made. In actual decisionmaking, alternatives are often examined sequentially. We may, or may not, know the mechanism that determines the order of procedure. When alternatives are examined sequentially, we may regard the first satisfactory alternative that is evaluated as such as the one actually selected". 
sua utilidade, mas tấo somente satisfazer seu objetivo. Quando confrontado com múltiplos objetivos, o tempo torna-se um constrangimento, já que o tempo gasto para alcançar um objetivo reduz necessariamente a quantidade de tempo disponível para alcançar o restante deles. Mais uma vez, Simon afirma que os agentes que enfrentam múltiplos objetivos só podem pensar em satisfazer metas limitadas dentro de suas necessidades. Nesse contexto, os agentes usam atalhos ou heurísticas para tomar decisões, o que significa que eles aprendem a partir de contextos de decisão anteriores e usam essas informaçóes em futuras decisóes. Seu modelo está resumido no Quadro 1.

Essa noção de indivíduos racionalmente limitados contrasta com a ampla concepção de racionalidade que se tornou popular nos anos 1950 e 1960 em economia (GIGERENZER; SELTEN, 2001). A racionalidade estava ligada à otimização, como se os indivíduos fossem capazes de adquirir e processar informaçóes de forma calculista. Os críticos consideraram esse modelo como implausível e que náo se encaixava na realidade da mente humana, propondo alternativamente o que denominam de teoria da racionalidade limitada. Na sua perspectiva, "racionalidade limitada significa repensar as normas, bem como estudar o comportamento real de mentes e instituiçóes" (GIGERENZER; SELTEN, 2001, p. 6, tradução minha) $)^{8}$.

O modelo de racionalidade limitada preparou o terreno para as análises psicológicas que o seguiram. A agenda de pesquisa mais consistente sobre os aspectos cognitivos da racionalidade humana foi estabelecida por Daniel Kahneman e Amos Tversky, dois psicólogos renomados que formularam uma estrutura de julgamento e processo de tomada de decisão conhecido como teoria prospectiva
(Prospect Theory, no original). Eles publicaram uma gama de resultados de experimentos psicológicos sobre racionalidade limitada. Muitas de suas descobertas reverberam em várias disciplinas (vez que o estudo da racionalidade é transversal a muitas ciências) e constituem a base da crítica cognitiva da TER. Os autores se concentram principalmente em indivíduos em vez de papéis para construir sua teoria do comportamento humano.

\begin{tabular}{|c|c|}
\multicolumn{1}{c}{} & $\begin{array}{c}\text { Quadro 1 } \\
\text { Modelo de Simon }\end{array}$ \\
\hline Modelo & Definiçáo \\
\hline $\begin{array}{c}\text { Funçôes de } \\
\text { utilidade } \\
\text { simplificadas }\end{array}$ & $V(s)=(1,0)$ ou $V(s)=(-1,0,1)$ \\
\hline $\begin{array}{c}\text { Aquisição de } \\
\text { informaçóes }\end{array}$ & $\begin{array}{c}\text { Os processos pelos quais os } \\
\text { agentes coletam informaçôes } \\
\text { devem ser incluídos como } \\
\text { parte do mapeamento do } \\
\text { conjunto } A \text { no subconjunto } S .\end{array}$ \\
\hline $\begin{array}{c}\text { Ordenamento } \\
\text { parcial dos } \\
\text { payoff }\end{array}$ & $\begin{array}{c}\text { Em vez de usar uma função escalar, } \\
\text { Simon sugere que uma função } \\
\text { vetorial seria mais representativa dos } \\
\text { payoff, especialmente quando se trata } \\
\text { de decisôes de grupo (cada membro } \\
\left.\text { possui sua própria funçấo } V_{i}\right)\end{array}$ \\
\hline
\end{tabular}

Fonte: Elaboração própria com base em Herbert Simon (1957)

A pesquisa de Kahneman e Tversky (2000) gerou muitas descobertas que contribuem para a atual compreensão da tomada de decisóes. Uma delas é que os indivíduos estão preocupados com ganhos e perdas, em vez de estados de bem-estar. Se se pudesse representar como eles ponderam ganhos e perdas, encontrar-se-ia uma curva em forma de $S$, ligeiramente mais acentuada no lado das perdas, o que leva à conclusão de que os indivíduos são avessos a elas. No entanto, a descoberta mais marcante 
de seus experimentos, e que eventualmente tornou-se parte de sua teoria da racionalidade limitada, é que os indivíduos estão sujeitos a efeitos de framing, independentemente de quáo sofisticados sejam os atores. De acordo com os autores, o framing viola a dominância $^{9}$ e, mais profundamente, os princípios de invariância ${ }^{10}$ das abordagens tradicionais da escolha racional. Eles afirmam que o princípio da invariância é normativamente essencial, intuitivamente convincente, mas psicologicamente inviável, porque os indivíduos estão sujeitos a efeitos de framing. Kahneman e Tversky (2000) construíram um modelo mais sofisticado baseado em pesos decisórios e sua relação com probabilidades declaradas. Os pesos das decisóes são não lineares e regressivos em relação às probabilidades declaradas. Essa característica leva a uma nova violaçáo do princípio da invariância, porque "o excesso de probabilidades reverte o padrão [do processo de tomada de decisão]: aumenta o valor dos 'chutes' longos [long shots] e amplifica a aversão a uma pequena chance de um perda severa" (KAHNEMAN; TVERSKY, 2000, p. 8 , tradução minha) ${ }^{11}$.

Muitos dos argumentos de Kahneman e Tversky giram em torno do conceito de framing. Seus experimentos são basicamente adaptados para desvendar a natureza desse fenômeno. Um experimento típico confronta indivíduos com pares de cenários probabilísticos, cujas declarações são escritas com mudanças sutis sobre como as probabilidades são atribuídas aos eventos. Uma avaliação cautelosa das declaraçóes deixaria claro que elas correspondem ao mesmo cenário, mas enquadrar a frase de maneiras diferentes leva a resultados diferentes nas escolhas dos indivíduos. É o que eles chamam de efeitos de framing. No entanto, os autores reconhecem que é impossível prever antecipadamente tais efeitos, o que significa que os experimentos deveriam ser realizados com indivíduos para entender e prever seus resultados. Sem isso, pode-se esperar apenas conclusôes vagas sobre o comportamento de um indivíduo, tais como: (1) os indivíduos valorizam a estabilidade sobre a mudança por causa do medo de perdas; (2) a instabilidade das preferências favorece a preferência pela estabilidade; (3) indivíduos valorizam a experiência real de resultados; (4) indivíduos valorizam a decisão em si; (5) indivíduos valorizam resultados que são certos em relação aos resultados que são incertos; (6) os indivíduos, ao classificar suas preferências e alternativas, concentram-se em seus elementos distintivos, o que pode levar a ordenamentos inconsistentes.

Essas descobertas foram essenciais para construir sua teoria de duas fases, conhecida como teoria prospectiva, que tenta explicar o raciocínio probabilístico dos indivíduos em vez de apenas as probabilidades de estados finais (como faz a EU). A primeira fase, a edição, consiste de uma análise preliminar dos prospectos, resultando em uma representação simples deles. Na segunda fase, a avaliação, os prospectos sáo avaliados e o de valor mais alto é escolhido. A edição consiste em três operaçôes: a codificação (ganhos e perdas são definidos em relação ao status de referência), combinaçôes (prospectos com probabilidades semelhantes e associados ao mesmo resultado

9 Dominância: se uma alternativa é melhor que outra em um estado e ao menos tão boa quanto em todos os outros estados, ela é dita dominante e, portanto, deve ser escolhida.

10 Invariância: diferentes representaçôes do mesmo problema de escolha/problema decisório devem produzir a mesma preferência (independência em relação à descriçẫo do problema).

11 " $[\mathrm{t}]$ he overweight of probabilities reverses the pattern [of the decision-making process]: it enhances the value of long shots and amplifies the aversiveness of a small chance of a severe loss". 
são combinados) e segregação (separação de quaisquer componentes de risco de componentes sem risco de um dado prospecto). Essa teoria baseia-se em mudanças de bem-estar porque os seres humanos estão cognitivamente melhor equipados para lidar com ganhos e perdas e não com magnitudes absolutas. Além disso, em uma segunda versão de sua teoria teoria prospectiva cumulativa -, Kahneman e Tversky (2000) afirmam que o processo de decisão é essencialmente construtivo e contingente, mas não necessariamente racional devido aos efeitos de framing. As aplicaçóes da teoria prospectiva no mundo real podem ser encontradas nos mercados de açôes (BARBERIS; HUANG; THALER, 2006; BENARTZI; THALER, 1995) e leilóes (ROSENKRANZ; SCHMITZ, 2007).

Seguindo as obras de Kahneman e Tversky e juntando-se a eles em outras pesquisas, Paul Slovic (2000) desenvolveu uma teoria de decisão integrativa que poderia explicar os efeitos das reversóes de preferências. Ele classifica as teorias de decisão em dois tipos: (1) a teoria da escolha sem risco, que se baseia na maximização da utilidade, informação perfeita, sensibilidade infinita a alternativas e racionalidade instrumental; e (2) a teoria da escolha arriscada, que considera os efeitos da incerteza e do comportamento dos modelos por meio da maximização do valor esperado.

Em seu relato da história das teorias de decisão, Slovic (2000, p. 491, tradução minha) aborda os problemas enfrentados pelas abordagens de escolha racional, principalmente alegando que as reversôes de preferências violam o princípio da invariância: "[o] princípio da invariância de procedimento é violado por reversốes de preferências que são induzidas pela mudança de um modo de induzir uma preferência para outro modo de resposta, formalmente equivalente" ${ }^{\prime 2}$. Na sua compreensão da formaçáo de preferências, os teóricos da escolha racional subestimaram a complexidade desse processo e as sutilezas do ordenamento de preferências. Em suas palavras (Slovic, 2000, p. 500, tradução minha):

Estratégias de construção [de ordenamentos de pre-
ferências] incluem ancoragem e ajuste, dependendo
da dimensáo proeminente, eliminando elementos
comuns, descartando diferenças não essenciais,
adicionando novos atributos ao quadro decisório,
para reforçar uma alternativa, ou de outra forma
reestruturando o problema de decisão para criar
dominância e, assim, reduzir conflitos e indecisão ${ }^{13}$.

Uma avaliação dos modelos de racionalidade limitada e comportamento cognitivo foi realizada durante o Dahlem Workshop, organizado em 1999 por Gerd Gigerenzer e Reinhard Selten na Universidade de Berlim. Os debates mais tarde resultaram na publicação de um volume com os trabalhos apresentados no workshop. Em sua avaliação, Gigerenzer e Selten (2001) veem dois equívocos sobre a racionalidade limitada: a otimização sob abordagem de restriçóes e o argumento de irracionalidade. O primeiro afirma que restriçôes internas e externas impedem que os atores adquiram informações - os chamados custos de transação. Os principais problemas com essa abordagem são: (1) os atores devem possuir conhecimentos profundos sobre os custos de transação; (2) indução

12 " $[\mathrm{t}]$ he principle of procedure invariance is violated by preference reversals that are induced by changing from one mode of eliciting a preference to another, formally equivalent, mode of response".

13 "[c] onstruction strategies [for preference orderings] include anchoring and adjustment, relying on the prominent dimension, eliminating common elements, discarding nonessential differences, adding new attributes into the decision frame in order to bolster one alternative, or otherwise restructuring the decision problem to create dominance and thus reduce conflict and indecision". 
retroativa infinita; (3) suposição errada sobre as habilidades de computação humana. $\mathrm{O}$ argumento da irracionalidade, por outro lado, afirma que a racionalidade limitada existe devido às discrepâncias nas normas e juízos humanos. Ambos os argumentos, no entanto, não conseguem entender que a racionalidade limitada é uma teoria, e não um resultado de um determinado modelo. Nesse sentido, os autores defendem que a teoria avançou ao longo dos anos, produzindo uma variedade de modelos de racionalidade limitada. Alguns desses modelos estão listados no Quadro 2, incluindo o próprio modelo de caixa de ferramentas adaptativas de Gigerenzer e Selten (2001) e a teoria das aspirações adaptativas de Selten (2001). Um teste recente desses modelos foi conduzido por Scheibehenne, Rieskamp e Wagenmakers (2013) usando uma abordagem bayesiana.

Quadro 2

Modelos de racionalidade limitada

\begin{tabular}{|c|c|}
\hline Modelo & Definiçáo \\
\hline $\begin{array}{l}\text { Regras simples para a } \\
\text { aquisiçấo de informaçấo }\end{array}$ & Procedimentos passo a passo para adquirir e ajustar informaçóes. \\
\hline Regra simples de pausa & $\begin{array}{l}\text { As regras simplificadas estabelecem o ponto em que não há necessidade de procurar } \\
\text { mais informaçôes. Elas não são baseadas na otimizaçấo. }\end{array}$ \\
\hline Regras decisórias simples & $\begin{array}{l}\text { Consiste na aplicação de regras simples na tomada de decisôes com base em informaçôes } \\
\text { adquiridas. }\end{array}$ \\
\hline $\begin{array}{l}\text { Caixa de ferramentas } \\
\text { adaptativas }\end{array}$ & $\begin{array}{l}\text { - Conjunto de regras e heurísticas; } \\
\text { - Heurísticas e cálculos rápidos; } \\
\text { - As heurísticas são específicas em relação ao contexto e ao ambiente (racionalidade } \\
\text { ecológica); } \\
\text { - Os métodos heurísticos são orquestrados de tal modo que refletem a importância das } \\
\text { motivaçôes e objetivos conflitantes. }\end{array}$ \\
\hline Aspiraçóes adaptativas & $\begin{array}{l}\text { Os agentes possuem múltiplos objetivos que são organizados como um vetor de níveis } \\
\text { de aspiraçáo. Os agentes, entâo, analisam a viabilidade de cada nível de aspiração, } \\
\text { movendo-os dentro do vetor de acordo com regras específicas. Novas alternativas podem } \\
\text { ser consideradas se os custos de busca por elas não impuserem constrangimentos. Os } \\
\text { agentes, portanto, continuarão a procurar alternativas que possam gerar níveis mais } \\
\text { altos de aspiraçâo até chegarem a um ponto em que não é mais viável continuar a } \\
\text { busca. Nesse ponto, os agentes tomam uma decisão. O modelo de Selten baseia-se na } \\
\text { racionalidade limitada, expressa nos seguintes elementos: } \\
\text { 1. Incomparabilidade de objetivos; } \\
\text { 2. Preferências procedimentais locais; } \\
\text { 3. Decisôes integradas aos recursos decisórios; } \\
\text { 4. Decisōes baseadas em expectativas qualitativas; } \\
\text { 5. Otimismo cauteloso na busca por alternativas e uso de expectativas qualitativas; } \\
\text { 6. Variáveis-objetivo relacionadas ao risco. }\end{array}$ \\
\hline
\end{tabular}

Fonte: Elaboração própria com base em Gerd Gigerenzer e Reinhard Selten (2001)

Fora do domínio da psicologia, outras críticas em termos normativos foram direcionadas à TER. Amartya Sen é um crítico notável da premissa de racionalidade, que, a seu ver, ignora as motivaçóes morais dos indivíduos (SEN, 1994; 1997). Além disso, Sen critica a abordagem canônica da escolha racional por sua falta de variáveis dependentes do contexto. 
Ele acredita que as escolhas podem ser dependentes do cardápio (menu-dependent $)^{14}$; consideraçóes de ética, epistemologias ou ordens de preferência dependentes do contexto podem desempenhar um papel crucial na definiçáo dos resultados de um processo de tomada de decisão. De acordo com Sen (1994, p. 385, tradução minha), "o comportamento dependente do cardápio, embora socialmente importante, tenderia a violar algumas propriedades comumente usadas de correspondência interna de escolha, ou 'consistência interna de escolha"'15. A escolha é, portanto, afetada por motivaçóes que violam os princípios de dominância e invariância, pois outras variáveis podem estar em jogo (como o sentido moral do dever). Além disso, Sen (1997) aborda a relevância do ato de escolha para a análise de maximizaçáo do comportamento. As questóes de responsabilidade ${ }^{16}$, especificamente o senso de responsabilidade do agente, associadas ao ato de escolha, podem alterar a ordem das preferências e a ordem dos resultados. Portanto, um modelo realista de escolha deve de alguma forma considerar os efeitos do ato de escolha e abandonar o objetivo final da otimização. Como consequência, a racionalidade deve explicar o senso de responsabilidade, vez que este é parte do ato de escolha e da busca do bem-estar. Segundo o autor (SEN, 1997, p. 753 , tradução minha):

Podemos valorizar não apenas a alternativa que eventualmente escolhemos, mas também o conjunto sobre o qual podemos exercer a escolha. Ao avaliar a "autonomia" de uma pessoa, não é adequado preocupar-se apenas se ela recebe o que escolheria se tivesse a oportunidade de escolher; também é importante que ela possa realmente escolher ${ }^{17}$.

Parte dessas críticas foram abordadas pelos teóricos da escolha racional em suas pesquisas. Os economistas comportamentais, como Herbert Gintis, buscaram outras abordagens para lidar com o comportamento humano, incorporando o comportamento cooperativo (GINTIS, 2000) e as normas sociais (GINTIS; HELBING, 2015), praticamente nas linhas da pesquisa de Robert Axelrod $(1984,1997)$ sobre a evolução da cooperação. Na ciência política, as respostas às críticas variaram. Muitos teóricos da escolha racional incorporaram comportamentos altruístas aos seus modelos (FEHR; FISCHBACHER, 2002; QUACKENBUSH, 2004); outros preferiram relaxar o ideal do universalismo, aceitando o universalismo parcial na TER (SATZ; FEREJOHN, 1994); e ainda há aqueles que favorecem uma visão de modelos como histórias, fábulas, mundos críveis que

14 A dependência do cardápio não deve ser confundida com framing. De acordo com Sen (1997, p. 752, traduçâo minha), "a influência do framing surge quando, essencialmente, a mesma decisão é apresentada de maneiras diferentes, enquanto o que consideramos aqui é uma variação real do problema de decisão, quando uma mudança do menu a partir do qual uma escolha deve ser feita faz diferença material. Na verdade, náo há inconsistência aqui, apenas a dependência do cardápio das classificações de preferências". No original: " $[\mathrm{t}]$ he influence of framing arises when essentially the same decision is presented in different ways, whereas what we are considering here is a real variation of the decision problem, when a change of the menu from which a choice is to be made makes a material difference. There is, in fact, no inconsistency here, only menu dependence of preference rankings."

15 “ $[\mathrm{m}]$ enu-dependent behavior, while socially important, would tend to violate some commonly used properties of internal correspondence of choice, or 'internal consistency of choice."”

16 Sen fornece uma lista de motivaçóes que podem afetar o ordenamento de preferências do agente: (1) reputação e efeitos indiretos; (2) compromissos sociais e imperativos morais; (3) efeitos diretos do bem-estar; (4) seguimento das regras convencionais.

17 "We may value not merely the alternative we eventually choose, but also the set over which we can exercise choice. In valuing the 'autonomy' of a person, it is not adequate to be concerned only with whether she receives what she would choose if she had the opportunity to choose; it is also important that she actually gets to choose herself." 
representam alguns aspectos do mundo real para transmitir uma narrativa e gerar previsóes (JOHNSON, 2017; RUBINSTEIN, 1991; SUGDEN, 2011). Em geral, o debate teórico gerou informaçôes valiosas que os teóricos da escolha racional poderiam implementar em seus estudos (HINDMOOR; TAYLOR, 2015, p. 6-7). Evidentemente, existem aspectos da abordagem psicológica que não podem ser facilmente incorporados aos modelos - os efeitos de framing são um deles -, seja porque eles são muito complicados e imprevisíveis para serem modelados; seja porque não melhorariam substantivamente a compreensão dos fenômenos políticos modelados. No entanto, o debate sobre premissas teóricas parece ter sido mais produtivo do que o empírico, sobre o qual me debruço a seguir.

\section{Críticas empíricas}

As críticas empíricas constituem um dos principais discursos contra a TER e suas capacidades explicativas. Nessa linha de argumentação, a teoria carece de previsibilidade dos fenômenos políticos ou, quando esta existe, apenas explica as previsóes triviais. Muitos dirigem suas críticas contra os modelos, alegando que eles são incapazes de representar a complexidade do mundo real. Outros se concentram nas incompatibilidades de evidências empíricas e premissas teóricas, a saber, a premissa de racionalidade.

Embora muitos pesquisadores tenham escrito sobre as falhas supostamente empíricas, optei por analisar a crítica de Green e Shapiro (doravante G\&S) e usá-la como uma referência das críticas empíricas contra a TER.
De acordo com Hindmoor (1998, p. 370, tradução minha):

$\mathrm{O}$ argumento de Green e Shapiro é importante e gerou uma controvérsia considerável porque é poderosamente afirmado e cuidadosamente defendido por meio de revisóes detalhadas da literatura sobre participação de eleitores, ação coletiva, comportamento legislativo e competição partidária. Também é sustentada pela identificação de 'patologias' metodológicas às quais os teóricos da escolha racional em busca de explicaçóes universalmente aplicáveis de fenômenos políticos alegadamente sucumbem ${ }^{18}$.

\section{Pathologies, de Green e Shapiro}

Talvez a obra de G\&S seja a crítica mais famosa, tendo deixado uma marca permanente nos debates de TER na ciência política (HINDMOOR, 1998). O livro foi publicado em 1994 e oferece uma coleção de "falhas empíricas" na abordagem da escolha racional, dividida em quatro campos principais: (1) o paradoxo da participação dos eleitores; (2) dilemas sociais e efeito carona; (3) comportamento legislativo; (4) competição eleitoral. Em cada capítulo, G\&S apresentam um resumo - às vezes anedótico - de modelos e pressupostos da escolha racional, que são seguidos por exemplos cirurgicamente escolhidos de como a teoria não explica os fenômenos políticos. Na verdade, os autores são profundamente pessimistas quanto às contribuiçôes empíricas da TER, como afirmam no início do livro (GREEN; SHAPIRO, 1994, p. 6, tradução minha):

Nosso foco aqui é sobre o poder empírico da TER.

Nós afirmamos que grande parte da fanfarra com a

18 “Green and Shapiro's argument is important and has generated considerable controversy because it is powerfully stated and carefully defended through detailed reviews of the literature on voter turnout, collective action, legislative behaviour and party competition. It is also underpinned by the identification of methodological 'pathologies' to which rational choice theorists in their quest for universally applicable explanations of political phenomena are alleged to succumb." 
qual a abordagem da escolha racional foi anunciada na ciência política deve ser vista como prematura uma vez que a pergunta é feita: o que esta literatura contribuiu para a nossa compreensão da política? ${ }^{19}$

G\&S partem de uma definição geral da abordagem da escolha racional, que eles consideram necessária para avaliar os campos mencionados em termos de suas epistemologias e metodologias. Ao fazê-lo, eles listam o que entendem como os elementos comuns de qualquer abordagem da escolha racional: (1) maximização da utilidade; (2) preferências estruturadas; (3) processos de decisão sob incerteza; e (4) individualismo metodológico. Eles também afirmam: "nas aplicaçóes empíricas, geralmente é compartilhado o pressuposto de que a racionalidade é homogênea em todos os indivíduos estudados" (GREEN; SHAPIRO, 1994, p. 17, tradução minha $)^{20}$. Depois de definir os termos de sua análise, eles apresentam cada falha separadamente levantando questôes sobre o problema da informaçáo, a natureza da explicação, o universalismo, as previsões e as evidências. Seus pontos principais estão listados no Quadro 3.

Nesse ponto, G\&S assumem uma posiçáo mais combativa em relaçáo à literatura sobre TER. Nenhum sucesso parece existir nos trabalhos dos teóricos da escolha racional, na opiniấo dos autores. Mesmo quando os teóricos da escolha racional tentam fornecer explicações sobre por que a previsão de um modelo não corresponde às evidências empíricas, G\&S qualificam sua atitude como anticientífica, vez que os teóricos parecem não admitir que o modelo falhou. Segundo eles, a estratégia central da escolha racional consiste na teorização post hoc sempre que os dados empíricos não se encaixam no modelo, recorrendo a essa estratégia em todos os casos analisados por G\&S. Seria uma espécie de lógica retrodutiva, na qual se tentam achar os condicionantes históricos e contextuais que produziram o desvio do resultado esperado, buscando encontrar uma plausibilidade $a d h o c$ para a narrativa da racionalidade.

No paradoxo da participação dos eleitores, G\&S afirmam que a TER não poderia fornecer uma explicação de por que as pessoas votam apesar da irracionalidade intrínseca de tal ato. Eles baseiam sua análise no modelo geral de participação dos eleitores, representado pela Inequação $1^{21}$.

$$
\begin{gathered}
\text { Inequaçáo } \mathbf{1} \\
p B+D>C
\end{gathered}
$$

$\mathrm{Na}$ Inequação $1, p$ representa a probabilidade associada aos benefícios obtidos por um eleitor quando o candidato vencer; $D$ significa a utilidade de lançar um voto e $C$ representa os custos de votação. Por meio de uma série de argumentos, os autores contestam o modelo e as soluçốes desenvolvidas pelos teóricos da escolha racional. O Quadro 4 lista as soluçóes e as críticas de G\&S.

Em suma, G\&S duvidam categoricamente que os modelos de TER possam realmente explicar a participação dos eleitores e recomendam os teóricos da escolha racional a abandonar o universalismo em favor de explicações alternativas.

19 "Our focus here is on the empirical power of RCT. We contend that much of the fanfare with which the RC approach has been heralded in political science must be seen as premature once the question is asked: What has this literature contributed to our understanding of politics?"

20 "[i]n empirical applications, the further assumption is generally shared that rationality is homogeneous across the individuals under study."

21 Inequaçôes são análogas a equaçóes, mas em vez de igualarem dois lados, apresentam uma desigualdade, expressa por $<$ ou $>$. 
Na visão dos autores, a TER falha porque está comprometida com os pressupostos irrealistas de maximização da utilidade e tomada de decisão estratégica aplicada a todos os eleitores. Esse compromisso não se encaixa com evidências empíricas. Curiosamente, eles recomendam os teóricos da escolha racional para construir suas próprias medidas e padróes, em vez de confiar nos dados de outros pesquisadores que não se adequam ao projeto de pesquisa da TER.

\section{Quadro 3}

\section{Problemas gerais da TER}

\begin{tabular}{|c|c|}
\hline Problema & Descriçáo \\
\hline Informação & $\begin{array}{l}\text { Mesmo quando os teóricos da escolha racional reconhecem que a informação é assimetricamente } \\
\text { possuída pelos agentes, eles enfrentam problemas para explicar: (1) a troca de informaçôes adicionais; } \\
\text { (2) o comportamento míope em face do postulado de ação estratégica. }\end{array}$ \\
\hline $\begin{array}{l}\text { Natureza da } \\
\text { explicaçáo }\end{array}$ & $\begin{array}{l}\text { G\&S criticam os teóricos da escolha racional por sua falta de consideração de intençóes como } \\
\text { causas sob um quadro psicológico de análise; e pelo universalismo da própria teoria, que eles } \\
\text { afirmam basear-se em equilíbrios irrealistas. }\end{array}$ \\
\hline Universalismo & $\begin{array}{l}\text { A TER seria bem-sucedida em domínios muito restritos em condiçóes específicas (universalismo } \\
\text { segmentado). No entanto, nunca poderia reivindicar o universalismo geral, pois naao foi capaz de } \\
\text { fornecer explicaçóes gerais sobre fenômenos políticos importantes. }\end{array}$ \\
\hline \multirow{2}{*}{ Previsōes } & $\begin{array}{l}\text { Previsóes escorregadias: como os modelos de escolha racional não capturam nuances psicológicas do } \\
\text { comportamento de um agente, eles não explicam situaçôes empíricas que não resultam em equilíbrio. }\end{array}$ \\
\hline & $\begin{array}{l}\text { Previsóes vagamente operacionalizadas: os modelos de escolha racional tratam principalmente de pontos } \\
\text { ou taxas discretas, enquanto que os testes empíricos são mais propensos a resultar em aproximaçóes. }\end{array}$ \\
\hline \multirow{3}{*}{ Evidência } & Viés seletivo: os teóricos da escolha racional selecionam evidências que confirmam suas previsôes. \\
\hline & Projeção da teoria: a evidência seria selecionada para satisfazer o modelo. \\
\hline & $\begin{array}{l}\text { Retirada estratégica de domínios em que a TER não fornece explicaçôes sólidas com base em } \\
\text { evidências empíricas. }\end{array}$ \\
\hline
\end{tabular}

Fonte: Elaboração própria com base em Green e Shapiro (1994)

\section{Quadro 4}

\section{Soluções ao paradoxo}

\begin{tabular}{|c|c|c|}
\hline Soluçáo & Descriçáo & Críticas de G\&S \\
\hline $\begin{array}{l}\text { Expansão do } \\
\text { termo D }\end{array}$ & $\begin{array}{l}\text { Os teóricos da escolha racional expandem a função } \\
\text { de utilidade representada por } D \text { para oferecer } \\
\text { explicaçóes alternativas para a participaçấo do eleitor. }\end{array}$ & $\begin{array}{l}\text { O termo } D \text {, mesmo com a expansão } \\
\text { da funçấo de utilidade, ainda não } \\
\text { contabiliza explicaçóes psicológicas. }\end{array}$ \\
\hline $\begin{array}{l}\text { Eliminação } \\
\text { do termo } \\
D \text { e termo } \varepsilon\end{array}$ & $\begin{array}{l}\text { A função de utilidade também pode ser eliminada da } \\
\text { desigualdade e os custos de votaçáo são considerados } \\
\text { muito pequenos }(C->\varepsilon) \text {. A probabilidade } p \text { é } \\
\text { assumida como suficientemente alta para manter a } \\
\text { desigualdade favorecendo a participaçáo do eleitor. }\end{array}$ & $\begin{array}{l}\text { A suposição original na TER diz que } p \text { é } \\
\text { muito baixa, o que significa que, mesmo } \\
\text { sob pequenos valores de } \varepsilon \text {, o lado direito } \\
\text { ainda seria maior que o lado esquerdo } \\
\text { da desigualdade. }\end{array}$ \\
\hline Teoria dos jogos & $\begin{array}{l}\text { Os jogos podem fornecer soluçóes para o paradoxo } \\
\text { sob informaçấo perfeita. }\end{array}$ & $\begin{array}{l}\text { Os equilíbrios entrariam em colapso sob } \\
\text { incerteza. }\end{array}$ \\
\hline $\begin{array}{l}\text { Utilidade } \\
\text { esperada }\end{array}$ & $\begin{array}{l}\text { Quanto mais próximas as eleiçōes, maior a influência } \\
\text { causal de } B \text {. }\end{array}$ & $\begin{array}{l}\text { Não há confirmação empírica de } \\
\text { dados agregados ou pesquisas; e não há } \\
\text { evidências da interação entre benefícios } \\
\text { coletivos e proximidade das eleiçôes. }\end{array}$ \\
\hline
\end{tabular}

Fonte: Elaboração própria com base em Green e Shapiro (1994) 
A ação coletiva é outro alvo dos ataques de G\&S. Eles definem a essência do dilema social como a busca de ganhos individuais produzindo resultados subótimos. O verdadeiro dilema social é causado pelo comportamento estratégico do carona. Os autores consideram isso a suposiçáo subjacente aos problemas de ação coletiva, embora reconheçam que diferentes configuraçóes de jogo produzem diferentes equilíbrios (GREEN; SHAPIRO, 1994, p. 77). No entanto, G\&S insistem que a TER não oferece soluçóes convincentes para problemas de ação coletiva porque não contabiliza os seguintes problemas: (1) comunicação entre atores; (2) mudanças nos benefícios coletivos esperados; (3) repetição do jogo e indução retrógrada. Ao afirmarem isso, os autores descartam qualquer trabalho que responda a essas questóes (e há inúmeros artigos e livros sobre jogos de sinalização, comunicação entre agentes, subjogos baseados em incertezas etc., que poderiam oferecer um contra-argumento a G\&S). Ironicamente, eles são vítimas de sua própria acusação por viés de seleção.

De acordo com G\&S, a TER náo pode explicar por que a cooperaçáo surge como resultado das interaçóes humanas quando confrontadas com um problema de ação coletiva. Na sua perspectiva, a TER trataria os agentes cooperativos como seres irracionais ou alegaria que a lógica da ação coletiva não pode ser extrapolada para a realidade de milhóes de pessoas. $\mathrm{O}$ Quadro 5 resume as principais críticas de G\&S nesse campo de pesquisa.

\section{Quadro 5}

\section{G\&S e os problemas da ação coletiva}

\begin{tabular}{|c|c|}
\hline Problema & Descrição \\
\hline $\begin{array}{l}\text { Ausência de grupos } \\
\text { de controle }\end{array}$ & $\begin{array}{l}\text { Sempre que os teóricos da escolha reacional realizam experimentos de problemas de açáo } \\
\text { coletiva, não há grupo de controle para avaliar a validade dos resultados encontrados no } \\
\text { grupo de tratamento. }\end{array}$ \\
\hline $\begin{array}{l}\text { Ausência de } \\
\text { mecanismos causais }\end{array}$ & A TER não explica como as variáveis estão conectadas. Isso resulta do problema anterior. \\
\hline $\begin{array}{l}\text { Modelos náo } \\
\text { testáveis }\end{array}$ & $\begin{array}{l}\text { No nível agregado, os modelos de TER náo podem ser testados e só podem oferecer } \\
\text { previsóes vagas sobre a contribuiçáo de cada agente para o esforço coletivo. }\end{array}$ \\
\hline Tautologias teóricas & $\begin{array}{l}\text { Resultam de teorização post hoc. Os teóricos da escolha racional convertem os fatores que } \\
\text { influenciam a açáo coletiva em incentivos. }\end{array}$ \\
\hline $\begin{array}{l}\text { Contradiçóes } \\
\text { experimentais }\end{array}$ & Os experimentos contradizem as teorias da ação coletiva. \\
\hline Previsóes diferentes & Modelos matemáticos similares produzem variados níveis de cooperação. \\
\hline
\end{tabular}

Fonte: Elaboração própria com base em Green e Shapiro (1994)

Os autores também abordam o campo do comportamento legislativo. G\&S definem essa literatura através da lente do paradoxo do voto sob a regra da maioria e a modelagem espacial. Os modelos espaciais preveem que a regra da maioria é vulnerável ao desenho da coalizão, resultando em votação cíclica.

Os autores inicialmente observam que os processos de decisão sob uma regra majoritária são baseados em múltiplas dimensóes, enquanto que os modelos espaciais são baseados em menos dimensóes (uma ou duas, evitando a complexidade do modelo). Eles desenvolvem e avaliam um modelo, tentando identificar suas falhas. Nesse ponto, o mesmo argumento de falta de evidência empírica ou evidência tendenciosa permeia suas conclusóes. G\&S se demonstram particularmente obcecados pelo trabalho 
de William Riker, acusando-o de narrativas históricas tendenciosas que só confirmam sua tese - uma acusaçấo que poderia ser facilmente aplicada a institucionalistas históricos e outros pesquisadores qualitativos. $\mathrm{Na}$ sua opinião, os teóricos da escolha racional apenas selecionam casos que se encaixam em seus modelos e não consideram os efeitos de diferentes contextos institucionais em suas análises, nem os traços psicológicos dos tomadores de decisão. Além disso, G\&S caracterizam experimentos de escotha racional como demonstraçóes, sem qualquer validade empírica devido à ausência de grupos de controle e a definiçôes imprecisas de instabilidade. Nas palavras dos autores (GREEN; SHAPIRO, 1994, p. 142, tradução minha):

Modelos espaciais de comportamento legislativo tendem a ignorar ou minimizar fenômenos como a persuasão de mudança endógena de preferências, solidariedade de grupo ou partido, tomada de posição e vários pagamentos paralelos fornecidos pela liderança. Ademais, estes modelos têm geralmente assumido um ambiente institucional bastante escasso no qual as regras procedimentais são poucas e os legisladores não incorrem em nenhum custo de transaçáo quando fazem uma proposta legislativa ou organizam coalizóes ${ }^{22}$.

Finalmente, e sem surpresa, G\&S não encontram nenhuma evidência de que a TER tenha contribuído de alguma forma para a compreensão empírica das campanhas e das estratégias dos candidatos. Esse campo, de acordo com sua revisão, preocupa-se principalmente com a modelagem da competição eleitoral. A principal conclusão alcançada pela teoria é que a competição eleitoral promove plataformas centristas. G\&S argumentam que as barreiras erguidas pelos teóricos da escolha racional para mensurar as crenças e motivaçôes dos candidatos restringem um projeto de pesquisa mais informativo que poderia melhorar a modelagem espacial. No entanto, eles reconhecem alguns avanços na teoria, como a multidimensionalidade, modelagem probabilística e uma visão ampliada dos objetivos dos candidatos. No entanto, a TER ainda deixaria aberta uma série de questóes relativas: (1) a preferências não reveladas nos grandes eleitorados; (2) aos vínculos entre questóes redistributivas e estratégias de campanha; (3) aos traços e imagens psicológicas dos candidatos; (4) à inconsistência interna das plataformas centristas. G\&S acreditam firmemente que os modelos espaciais não são capazes de abordar essas questóes sem perder a parcimônia e a estabilidade empírica no processo.

Este breve resumo descreveu as acusaçôes de G\&S contra TER. Ao apontarem as promessas não cumpridas dentro da proposta dedutiva da TER, os autores esperam ter demonstrado que os modelos dedutivos náo são orientados a problemas, ou, pelo menos, não no sentido de buscarem explicar fenômenos reais sob a ótica de uma análise dedutiva. Porém, sua desconfiança quanto às capacidades explicativas da TER faz com que eles negligenciem obras que conseguiram oferecer previsões longe de serem consideradas banais, previsōes estas baseadas no caráter dedutivo das abordagens de escolha racional. A obsessão com o teste empírico de casos específicos ignora o tipo de explicação gerada por modelos de escolha racional, qual seja, a de fenômenos gerais em níveis de granularidade mais baixo e que se observam em diferentes casos (LIMA, 2018). Além disso, concentrando-se em um conjunto

22 "Spatial models of legislative behavior have tended to ignore or downplay such phenomena as persuasion of endogenous preference change, group or party solidarity, position taking, and various leadership-supplied sidepayments. In addition, these models have generally presupposed a rather sparse institutional environment in which procedural rules are few and legislators incur no transaction costs when they make legislative proposal or organize coalitions". 
de casos escolhidos cirurgicamente, G\&S não conseguiram capturar a diversidade de modelos e abordagens de TER. As reaçóes contra o seu livro apresentam uma visão alternativa da teoria e das perspectivas da TER, fornecendo descriçōes e explicaçôes bem-sucedidas de fenômenos políticos.

\section{Reaçôes a Pathologies e outras críticas}

Logo após a publicação de Pathologies, um debate se desenvolveu na Critical Review: $A$ Journal of Politics and Society. Treze cientistas políticos foram convidados a oferecer suas opiniôes e impressões sobre o livro de G\&S em um simpósio em 1995. Suas ideias são valiosas na medida em que proporcionam uma compreensão mais ampla da TER e as críticas que esta enfrenta.

Grande parte do desacordo orbitou em torno de equívocos sobre a TER, bem como sobre o tipo de ciência defendida por G\&S. Morris Fiorina (1995), por exemplo, discorda da abordagem de G\&S para a ciência e testes empíricos, alegando que os autores utilizam o teste estatístico como a única métrica para avaliar a validade de uma teoria ou um campo de pesquisa. Eles ignoram outras formas de validação empírica e até a possibilidade de falhas empíricas como parte do métier científico. Fiorina também contesta a afirmaçáo universalista da TER sobre a qual G\&S basearam suas análises. Ela pode ser verdadeira sobre alguns teóricos, como era verdadeira para outros cientistas políticos, como David Easton, que eram bastante ambiciosos sobre seus projetos teóricos e metodológicos. No entanto, a TER é uma comunidade diversificada, que só concorda com a premissa de que os agentes se comportam orientados a objetivos - o resto é discutível em termos de abordagens teóricas e metodológicas. Nesse contexto, poucos poderiam ser acusados de aspiraçôes universalistas (COX, 2004; ERIKSSON, 2011; SNIDAL, 2006).

Susanne Lohmann (1995, p. 127, tradução minha), por outro lado, afirma assertivamente que G\&S não entendem a TER:

quando o argumento de Green e Shapiro sobre dilemas coletivos e carona é formalizado, ele se revela profundamente falho e, em muitos aspectos, totalmente falso. Seu erro é bastante comum: eles classificam erroneamente uma variedade de dilemas coletivos como dilemas de prisioneiros ${ }^{23}$.

Na sua defesa da TER, ela afirma que a teoria fornece modelos matemáticos rigorosos sobre processos políticos e instituiçôes que permitem testar hipóteses. Na teoria dos jogos, muitos modelos diferentes foram concebidos para entender melhor como os atores pensam suas estratégias. Esses jogos são baseados em configuraçôes diferentes e Lohmann considera um mal-entendido na obra de G\&S que todos os problemas de ação coletiva sejam tratados sob o mesmo véu do dilema dos prisioneiros. Ela também contesta a afirmação de G\&S de que as obras que analisaram não haviam considerado explicaçóes alternativas: a autora afirma que outras explicaçôes foram oferecidas, especialmente devido ao fato de que os pressupostos da própria TER (como racionalidade, comportamento estratégico, maximização de utilidade) fornecem um ponto de partida para comparar os resultados teóricos com a evidência empírica. Uma clara ilustração desse ponto é que não se pode pensar em altruísmo e cooperação sem compará-los aos resultados da TER.

23 "When Green and Shapiro's argument concerning collective dilemmas and free riding is formalized, it turns out to be deeply flawed and in many respects outright false. Their mistake is common enough: they misclassify a variety of collective dilemmas as prisoner's dilemmas." 
Mais recentes contribuiçôes à TER foram feitas por Keith Dowding. Em seu artigo "Is it rational to vote", Dowding (2005) apresenta cinco categorias gerais de soluçóes para o paradoxo da participação do eleitor: (1) solução marginalista; (2) solução de termo $C$; (3) solução de termo $B$; (4) solução de termo $p$; (5) solução de termo $D$. Elas são baseadas na Inequação 1 apresentada por G\&S e abordam o problema de diferentes maneiras. De acordo com Dowding (2005, p. 445, tradução minha), "de maneira global, a evidência empírica mostra que a fórmula simples da teoria da decisão captura algumas das consideraçôes na decisão de votar. Ela tem alguma força explicativa" ${ }^{24}$.

As soluçôes do termo $D$ são particularmente interessantes no contexto da obra de G\&S. Eles constantemente afirmam que os modelos de TER não são responsáveis por motivações privadas que podem ser decisivas para a participaçẫo dos eleitores, mas desconsideram as tentativas dos teóricos de escolha racional de incorporar tais motivaçóes por meio do termo $D$. Como Dowding afirma (2005, p. 453, tradução minha):

No entanto, a resposta " $D$ ", apesar de ser simples, apesar de ser empiricamente verificada por evidências de preferências declaradas, consistente com a evidência de dados agregados e, se náo devidamente testadas, corroboradas pelas evidências de Barry e Knack, não é muito favorável entre os cientistas políticos, sejam os defensores ou críticos da escolha racional. Por quê? Porque eles querem razôes mais profundas ${ }^{25}$.

Razóes mais profundas podem não ser fornecidas pela própria ciência política, vez que a disciplina é particularmente eficiente em prever fenômenos globais. O tipo de preocupação levantada por G\&S pode ser explicada pela psicologia política, que não é exatamente o escopo da disciplina.

No entanto, a TER ainda enfrentou outras acusaçôes sobre seu individualismo metodológico (a TER se concentra demais no indivíduo, ignorando outros aspectos de sua formação de preferências); preferências fixas (os indivíduos mudam suas preferências de acordo com o estado do mundo); racionalidade instrumental (a TER estaria comprometida com questôes normativas que são egoístas e/ou orientadas à direita do espectro político, sendo intrinsecamente incompatíveis com outras perspectivas, como o socialismo) e a modelagem simplista (DOWDING; HINDMOOR, 1997). Porém, é importante notar que a TER está preocupada com agentes racionais, suas açôes e como essas açōes provocam resultados sociais específicos, dados esses axiomas. Os agentes são tratados como racionais nos papéis que desempenham, dada uma configuração que restringe suas expectativas e açóes. Nesse sentido, as abordagens e os modelos de escolha racional não tratam do motivo pelo qual Valentina decidiu votar em vez de ficar em casa num domingo chuvoso; nem por que os moradores de uma determinada rua superaram o dilema do carona e concordaram em contratar um serviço para inspecionar e cortar árvores mortas. Contudo, ela fornece previsóes sobre agentes racionais que desempenham seus papéis em contextos nos quais um conjunto de restriçôes impóe ganhos e perdas às açôes dos indivíduos.

A importância da TER reside precisamente nessa conexão entre processos de nível micro

24 "[o]verall the empirical evidence shows that the simple decision-theoretic formula does capture some of the considerations in the decision to vote. It has some explanatory force."

25 'Nevertheless the ' $\mathrm{D}$ ' answer, despite being simple, despite being empirically verified by stated preference evidence, consistent with aggregate data evidence, and, if not properly tested, corroborated by Barry's and Knack's evidence, does not find much favour among political scientists whether rational choice advocates or critics. Why? Because they want deeper reasons." 
de processos decisórios e fenômenos de macronível. Todas as abordagens em TER compartilham a mesma preocupação com a explicação dos resultados sociais com base nas açóes dos indivíduos. Por tal razão a TER baseia-se no individualismo metodológico em suas análises. Como Dowding e Hindmoor (1997, p. 452, tradução minha) sugerem, "os resultados sociais resultam da ação individual e, embora isso náo implique necessariamente que toda explicaçáo seja causal, sugere que a história causal total deve pelo menos ser mediada através das açôes dos indivíduos". A agência é baseada em indivíduos, mas a estrutura em que atuam fornece incentivos e restriçôes à sua ação. Para cada estrutura e contexto diferentes, podem ocorrer resultados diferentes. Os modelos de escolha racional, estabelecendo preferências e estratégias de atores em um determinado quadro institucional, fornecem a ligação entre agência e estrutura. Como Dowding (2017, p. 53, tradução minha) afirma:

os agentes humanos são fixos de alguma forma nós assumimos seus desejos e crenças (que juntos formam suas preferências) como dados - e então examinamos como eles se comportam, dado o ambiente em que operam. Os resultados formais na teoria das escolhas sociais e racionais demonstram que preferências idênticas levam a diferentes resultados, dadas diferentes regras de agregação. Segue-se que podemos esperar ver diferentes resultados devido à hierarquia do que à tomada de decisóes negociadas, diferentes resultados de diferentes sistemas eleitorais, e assim por diante. Agora, deve ser reconhecido, mesmo nesse primeiro nível, que o exame dessas preferências fixas precisa levar em consideração as relaçôes estruturais ou institucionais que existem. Os agentes individuais podem esperar responder a diferentes relações institucionais com as diferentes estratégias disponíveis para eles: isto é, eles respondem estrategicamente. Qualquer forma institucional pode ser manipulada de uma forma ou de outra ${ }^{26}$.

Os indivíduos, portanto, são dotados de preferências consistentes, que constituem os blocos de construção de suas açóes. Por consistência, entende-se que as preferências são ordenadas e transitivas, permitindo a derivação das funçôes de utilidade e a configuração do modelo. Os indivíduos tomam decisôes com base nos princípios de maximização da utilidade e comportamento estratégico. Eles são autointeressados na medida em que essa suposição evita tautologias explicativas ${ }^{27}$. Os indivíduos

26 "human agents are fixed in some manner - we take their desires and beliefs (which together form their preferences) as given - and then examine how they behave given the environment in which they operate. Formal results in social and rational choice theory demonstrate that identical preferences lead to different outcomes given different aggregation rules. It follows that we can expect to see different outcomes from hierarchy than from bargained decision-making, different results from different electoral systems, and so on. Now it must be recognized, even at this first level, that examination of these fixed preferences needs to take into account the structural or institutional relationships that exist. Individual agents can be expect to respond to different institutional relationships with the different strategies available to them: that is, they respond strategically. Any institutional form can be manipulated in one way or another."

27 A hipótese de autointeresse é comumente assumida nos modelos de escolha racional, embora possa ser descrita em diferentes termos para melhor atender às idiossincrasias de cada caso. $\mathrm{O}$ autointeresse geralmente é justificável não apenas como uma ferramenta para evitar tautologias, mas também porque é: (1) uma descrição crível da natureza humana; (2) realista em certos contextos; (3) fiel ao funcionamento da racionalidade; (4) metodologicamente útil; (5) pragmática. Evidentemente, os opositores da TER criticam a suposição de interesse próprio por ser uma descrição parcial do comportamento humano e da interação coletiva, muitas vezes mencionando o comportamento altruísta como um contra-argumento. No entanto, como Eriksson (2011, p. 96, tradução minha) afirma: "Antes de dizer qualquer coisa sobre a hipótese de autointeresse como tal, devemos notar que grande parte da literatura de escolha racional não faz qualquer suposição sobre motivação, mas apenas sobre a estrutura das preferências. Isso tem uma tendência a ser esquecido na crítica geral contra assumir que os agentes se interessam por si mesmos" " Before saying anything about the self-interest assumption as such, we should note that much of the RC literature does not make any assumptions about motivation, but only about the structure of preferences. This has a tendency to be forgotten in the general criticism against assuming that agents are self-interested']. Motivaçóes, portanto, náo devem ser confundidas com interesse próprio. 
também são racionais, o que significa que suas açóes seguem seus desejos e crenças da maneira mais eficiente para atingir seus objetivos.

Nesse contexto, a maioria das críticas tende a perder o ponto de por que são necessários pressupostos robustos para produzir modelos explicativos. Se os modelos de escolha racional têm algo a dizer, isso só é possível devido às suas premissas claras, que permitem a derivação lógica de hipóteses e previsóes. Mesmo G\&S reconhecem que o compromisso com o individualismo metodológico, a maximização da utilidade e o conceito de racionalidade tornam a TER mais "sistemática", "sofisticada" e "rigorosa” (GREEN; SHAPIRO, 1994, p. 3-10 apud HINDMOOR, 1998). Isso só é possível porque a TER tenta revelar mecanismos explicativos, o que é alcançado por meio da modelagem. Os modelos, portanto, são valiosos e eficazes na medida em que eles explicam os fenômenos políticos em termos das implicaçóes lógicas envolvidas em suas expressóes matemáticas. G\&S náo conseguem capturar essa sutileza devido à sua compreensão míope de explicação, como uma série de tiques em uma lista de verificação de predição versus evidência. Ironicamente, pela mesma lógica, grande parte da pesquisa em ciência política poderia ser questionada, vez que sempre haverá um caso extra para adicionar como contrafatual ou contra-argumento a essa lista de verificação.

As críticas mencionadas, no entanto, abriram portas para potenciais alternativas à TER e o século XXI já testemunhou o surgimento de abordagens teóricas e metodológicas nesse sentido. $\mathrm{O}$ institucionalismo histórico, por exemplo, centrou-se em questóes de estrutura e agência e como elas são afetadas pelo contexto histórico, tempo e processos dependentes da trajetória (LIMA; MÖRSHBÄCHER, 2017; THELEN; MAHONEY, 2015). O próprio Movimento Perestroika, que abordarei na próxima seção, também ofereceu soluçôes alternativas para pesquisa quantitativa e para a
TER (FLYVBJERG, 2006; JACKSON, 2006; SCHRAM; CATERINO, 2006; SCHWARTZ-SHEA, 2006; SHAPIRO; SMITH; MASOUD, 2004). Evidentemente, os teóricos da escolha racional reagiram a esses avanços e muitos conseguiram tirar lições valiosas das alternativas e críticas mencionadas. As narrativas analíticas, por exemplo, são um dos campos em que a TER e o institucionalismo histórico se sobrepóem para oferecer explicaçóes históricas e de teoria dos jogos aos fenômenos políticos (BATES et al., 1998; THELEN, 1999). Da mesma forma, os desenvolvimentos em economia comportamental e neuroeconomia têm-se apoiado em modelos de escolha racional no tratamento da mente humana (GINTIS; HELBING, 2015; GLIMCHER, 2011). Como se pode ver, os teóricos da escolha racional estão conscientes de críticas e falhas em seus modelos e vêm buscando várias ferramentas alternativas para refiná-los.

\section{A TER e as hierarquias de conhecimento}

Em 2000, a academia americana de ciência política foi abalada por um e-mail anônimo enviado aos membros da APSA. O Sr. Perestroika, que assinou o manifesto, questionava as hierarquias do conhecimento promovidas pela APSA em seus fóruns e, especialmente, em seus periódicos, mais especificamente a APSR. A TER não foi diretamente acusada como uma preferência epistemológica, mas o Sr. Perestroika questionou a validade da teoria dos jogos e outros modelos como ferramentas para analisar fenômenos políticos. Cito no original:

4) Why are a few men who make poor game-theorists and who cannot for the life-of-me compete with a third grade Economics graduate student - WHY are these men allowed to represent the diversity of methodologies and areas of the world that APSA "purports" to represent? 
[... 10) At a time when the free market models of economics are being challenged in IMF and World Bank, discredited in much of Asia, and protested by numerous groups; why are simple, baby-stuff models of political science being propagated in our discipline? If these pseudo-economists know their Maths so well-let them present at the University of Chicago's Economics Workshop-I assure you every single political science article will be trashed and thrown into the dustbin. Then why are these people allowed to throw their weight around based on undergrad maths and stats-an Econ 101? We are in the business of Political Science and not failed Economics. ${ }^{28}$

O manifesto reativou os velhos cismas na disciplina, ecoando entre os críticos da orientação supostamente quantitativa e de escolha racional da APSA (HINDMOOR; TAYLOR, 2015). Ao longo dos anos subsequentes, foram realizadas grandes mudanças para acomodar os interesses daqueles que se viram marginalizados na nova era de dados quantitativos e modelagem matemática e estatística. O lançamento de uma nova e mais plural revista, a Perspectives on Politics (POP), foi uma das iniciativas da APSA para acomodar os descontentes (HOCHSCHILD, 2003). A POP publica uma variedade de trabalhos qualitativos e interpretativos, e passou a se definir como um periódico que contrabalança a orientação de escolha quantitativa e racional da APSR $^{29}$.

Juntamente com as críticas da década de 1990, o Movimento Perestroika teve impacto na visibilidade e aceitação das obras dos teóricos da escolha racional, especialmente nos mais prestigiados periódicos da ciência política. Como mencionei anteriormente, G\&S iniciam seu Pathologies examinando a quantidade de artigos orientados para a escolha racional publicados na APSR, o que os leva a suas críticas contra a proeminência da TER nos artigos publicados pela revista principal da APSA. Três anos depois, Pippa Norris (1997) publicaria um artigo no

28 4) Por que poucos homens que são fracos teóricos dos jogos e que não conseguem competir com um estudante de pós-graduaçáo do terceiro ano de Economia - POR QUE estes homens têm o direito de representar a diversidade de metodologias e áreas do mundo que a APSA “pretende” representar?

[... 10) Em uma época em que os modelos econômicos de livre mercado estáo sendo questionados no FMI e no Banco Mundial, desacreditados em boa parte da Ásia, e alvo de protestos de inúmeros grupos; por que modelos de ciência política simples, de criança estão sendo propagados na nossa disciplina? Se estes pseudoeconomistas conhecem sua matemática tão bem - deixe-os apresentarem no Workshop de Economia da Universidade de Chicago -, eu garanto a vocês que todo artigo de ciência política será destruído e jogado no lixo. Então, por que estas pessoas têm o direito de jogar seu peso com base em matemática e estatística de graduação - uma Econ 101 ? Nós fazemos Ciência Política, e nâo Economia falida.

Jeffrey Isaac, ex-editor do POP, publicou uma nota editorial na qual ele define claramente o "perfil editorial distintivo" dessa revista. Isaac (2015, p. 931, tradução minha) escreve: "Recebemos muitas submissóes que procedem nessa maneira de 'ciência normal', algumas delas muito boas, e as revisamos periodicamente internamente e geralmente as devolvemos a seus autores com incentivo para enviar suas obras a um dos muitos periódicos em nossa disciplina - APSR, AJPS, JoP, CPS - que tende a publicar 'descobertas' no formato padrão da ciência normal.” No original: “We receive many submissions that proceed in this 'normal science' manner, some of them very good, and we expeditiously review them internally and typically return them to their authors with encouragement to submit their pieces to one of the many journals in our discipline-APSR, AJPS, JoP, CPS-that does tend to publish 'findings' in the standard, normal science format".

29 Jeffrey Isaac, ex-editor do POP, publicou uma nota editorial na qual ele define claramente o "perfil editorial distintivo" dessa revista. Isaac (2015, p. 931, tradução minha) escreve: "Recebemos muitas submissóes que procedem nessa maneira de 'ciência normal', algumas delas muito boas, e as revisamos periodicamente internamente e geralmente as devolvemos a seus autores com incentivo para enviar suas obras a um dos muitos periódicos em nossa disciplina APSR, AJPS, JoP, CPS - que tende a publicar 'descobertas' no formato padrão da ciência normal." No original: "We receive many submissions that proceed in this 'normal science' manner, some of them very good, and we expeditiously review them internally and typically return them to their authors with encouragement to submit their pieces to one of the many journals in our discipline-APSR, AJPS, JoP, CPS-that does tend to publish 'findings' in the standard, normal science format." 
European Journal of Political Research (EJPR), comparando as tendências teóricas e metodológicas na APSR, EJPR e Political Studies. De fato, os dados de Norris confirmam que os artigos de escolha racional demonstraram uma presença crescente nas páginas da APSR na década de 1990, respondendo por aproximadamente 30\% de todos os artigos publicados na revista (contra $17 \%$ e $16 \%$ nas décadas de 1970 e 1980 , respectivamente). No entanto, afirmar que os teóricos da escolha racional tinham planos hegemônicos em direçẫo à disciplina é antes uma falácia do que um fato, especialmente quando se presta atençấo à tendência quantitativa dominante que não está ligada à TER nem à modelagem formal.

Os anos 2000 testemunharam um declínio dos modelos de escolha racional nas duas principais revistas americanas, a saber, a American Journal of Political Science (AJPS) e a APSR. Na APSR, o número de artigos aceitos de teoria formal tem sido consistentemente inferior a $13 \%$ desde 2010 , quando tomados unicamente, com um cenário ligeiramente melhor quando combinados com testes quantitativos (ISHIYAMA, 2015). A AJPS publica consistentemente artigos quantitativos (codificados como Estatísticos-Empíricos), como mostrado no Gráfico $1^{30}$, o que teve efeito na proporção de submissóes sobre a teoria formal (codificada como Racional-Dedutivo e MatemáticoEmpírico). De acordo com o relatório dos editores (JACOBY et al., 2017), as obras de "Metodologia e teoria formal" representaram quase 7,5\% do total de submissóes desde 2011.

\section{Gráfico 1}

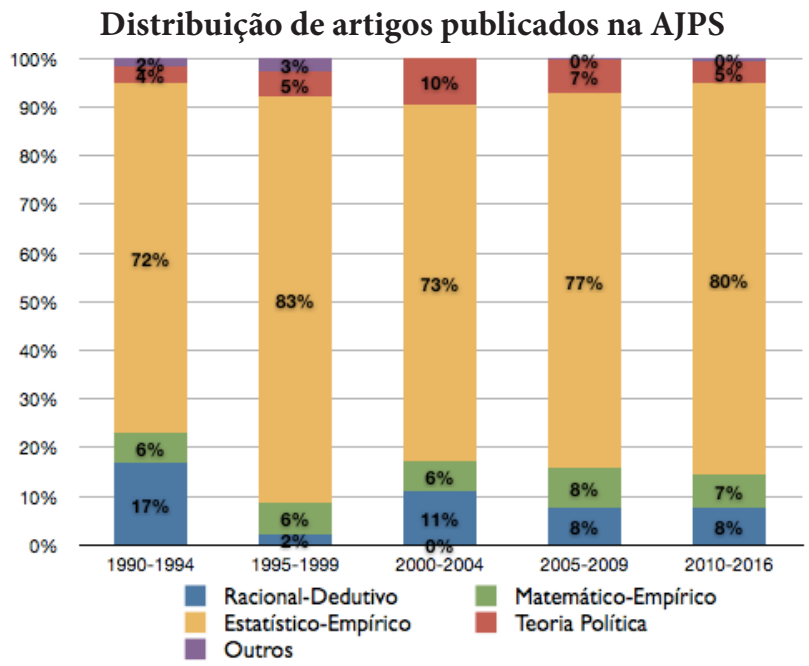

Fonte: Elaborado pelo autor com base no projeto Hierarquias de Conhecimento na Ciência Política, 2017

30 Esses dados fazem parte de um projeto bibliométrico conjunto realizado com Melina Mörschbächer (UFRGS). Nós codificamos à mẫo todos os artigos nas revistas AJPS, APSR, JTP, POP e IPSR de 1990 a 2016. Nós classificamos suas abordagens metodológicas com base nas informaçôes fornecidas nas seçôes de resumos e/ou desenho de pesquisa. O código significa: Teoria política: discussōes teóricas sobre filosofia política, teoria política normativa e teoria política positiva; Racional-Dedutivo: modelos formais sem testes empíricos, principalmente modelos de escolha racional; Estatístico-Empírico: análises estatísticas baseadas em estatísticas inferenciais ou descritivas; Matemático-Empírico: aplicaçóes empíricas de modelos formais; Outros: abordagens metodológicas que nấo se enquadram em nenhuma das categorias anteriores. 


\section{Gráfico 2}

Distribuição de artigos na JTP

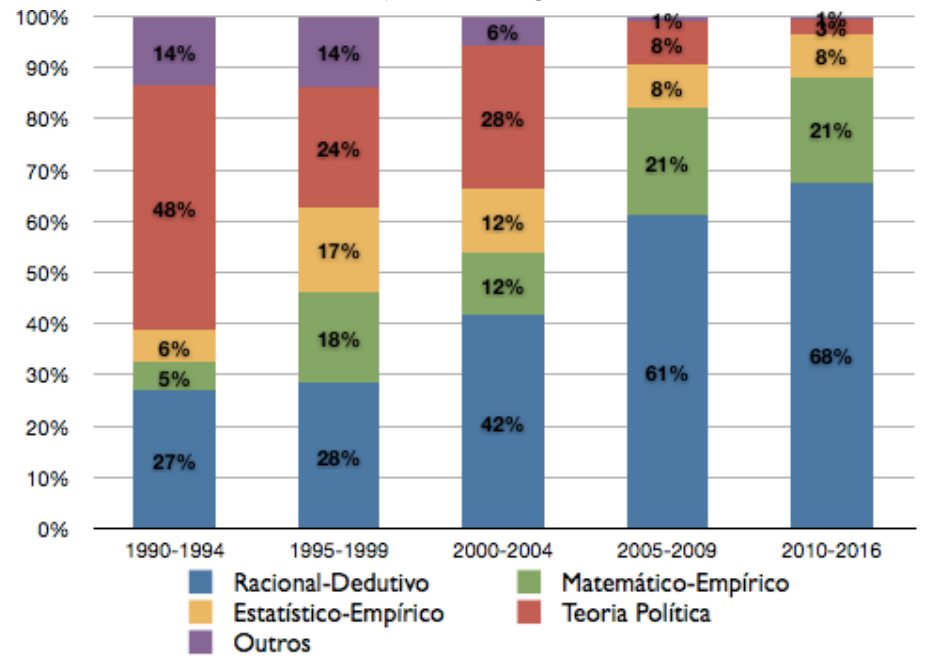

Fonte: Elaborado pelo autor com base no projeto Hierarquias de Conhecimento na Ciência Política, 2017

Como revistas de alto prestígio e fator de impacto na disciplina, as tendências observadas na APSR e AJPS suscitam preocupaçóes sobre as perspectivas da teoria formal. Apesar da recente onda de testes de modelos em ciência política (BAS; SIGNORINO; WALKER, 2008; CLARKE; SIGNORINO, 2010; MONROE et al., 2015), ainda há muita discussão sobre a necessidade de modelos formais puros. Os filósofos da ciência, economistas e cientistas políticos participam desse debate, especialmente em termos das capacidades explicativas dos modelos (ALEXANDROVNA; NORTHCOTT, 2013; CARTWRIGHT, 2010; HAUSMAN, 2005, 2013; JOHNSON, 2014, 2017; MÄKI, 2013; MORTON, 1999; REISS, 2013; SUGDEN, 2011, 2013). Nesse processo, as hierarquias do conhecimento favoreceram testes estatísticos puros, os quais, embora necessários, não são a única maneira de avaliar a robustez do modelo e a validade de seus pressupostos. Além disso, testar um modelo formal requer uma derivação consistente de um modelo estatístico a partir dos pressupostos originais, uma tarefa que exige compreensão teórica e treinamento matemático e estatístico (SIGNORINO, 2007; SIGNORINO; YILMAZ, 2003).

Evidentemente, mesmo diante de questôes tão metodológicas, as obras de teóricos da escolha racional e de modelos formais ainda são apreciadas em periódicos como Public Choice, Social Choice and Welfare e Journal of Theoretical Politics (JTP) ${ }^{31}$, bem como em revistas de economia. O Gráfico 2 apresenta a distribuição de artigos de acordo com sua abordagem metodológica na JTP ${ }^{32}$.

31 De acordo com o ex-editor do JTP, Keith Dowding, a revista incentivou os teóricos de modelos formais a enviarem seus artigos para a revista, visto que eles estavam vendo suas propostas serem rejeitadas por revistas mainstream.

32 Mesmo banco de dados. 
$\mathrm{O}$ quadro parece muito mais animador para os modelos formais, vez que o jornal de fato favorece esse tipo de abordagem. Além disso, na era de big data, a teoria formal pode desempenhar um papel importante na definição dos fundamentos para a validação dos achados de enormes quantidades de dados. Como Clark e Golder (2015, p. 67, tradução minha) sugerem, "as conclusóes resultam de uma combinação de dados e premissas teóricas - sem pressupostos, os dados são dados"33 e "a escolha que o pesquisador enfrenta não está entre indução ou dedução, nem descrição e explicação, mas entre observação orientada por teorização consciente e observação guiada por teorização inconsciente" 34 .

\section{Conclusão}

A TER enfrentou críticas de várias fontes ao longo de sua história. Debates sobre os pressupostos dos modelos de escolha racional, testes empíricos e a utilidade da teoria como um quadro preditivo foram abordados de diferentes maneiras pelos teóricos da escolha racional. Algumas dessas críticas poderiam ser acomodadas como parte do edifício da TER - como a necessidade de mais testes empíricos -, mas muitas outras não poderiam, devido à sua natureza, ser implementadas nos domínios teóricos da escolha racional sem colapsar em modelos intratáveis. Esse parece ser o caso das teorias cognitivas do comportamento humano, que exigem demasiadas informaçóes sobre o funcionamento da mente humana. No entanto, os trabalhos recentes em economia comportamental e neuroeconomia parecem abordar as complexidades do comportamento humano usando abordagens metodológicas da TER, abrindo espaço para novos modelos.

A crítica na ciência política mostrou-se preocupada principalmente com a validade empírica dos modelos de escolha racional. Essa é uma forma de julgar os modelos, mas não o único caminho, vez que eles servem para diferentes fins, dependendo de como são concebidos. Os críticos podem ter razão sobre os pressupostos simples e às vezes "pouco realistas" da TER, mas sempre que fornecem alternativas na psicologia cognitiva ou na pesquisa qualitativa, também são assumidos pressupostos "pouco realistas". A diferença é que a TER fornece o argumento teórico necessário (individualismo metodológico, estrutura de preferências, incentivos e constrangimentos à ação) para prosseguir com sua análise e, mais importante, desenvolver modelos a partir dos quais se possam derivar previsóes sobre fenômenos do mundo real. Além disso, os trabalhos de escolha racional são claros sobre o seu conteúdo teórico e metodológico, visto que geralmente apresentam as deduçóes e previsóes derivadas do modelo. Portanto, uma avaliação adequada da TER deve levar em consideração esses aspectos em vez de confiar em pesquisas baseadas em casos específicos. Não se pode julgar o valor de um modelo baseado em preconceitos sobre como a pesquisa deve ser concebida, pois uma disciplina plural de fato analisa fenômenos políticos usando várias ferramentas, cada uma adequada para responder às questóes de pesquisa colocadas pela sua base teórica.

Finalmente, a era quantitativa promoveu simultaneamente novos desafios e oportunidades para a TER. Apesar da presença decrescente de modelos em revistas prestigiadas na disciplina, eles podem oferecer os instrumentos

33 "conclusions result from a combination of data and theoretical assumptions - without assumptions, data is data."

34 "the choice confronting the researcher is not between induction or deduction, or description and explanation, but between observation guided by conscious theorizing and observation guided by unconscious theorizing." 
necessários para melhorar desenhos de pesquisa. Os pressupostos da escolha racional, combinados com a matemática dos modelos formais, fornecem a base para pensarmos sobre mecanismos explicativos e como as variáveis interagem para gerar resultados. Além disso, os modelos são baseados em contextos (ou configuraçóes), que são essenciais para enquadrar uma questão de pesquisa e começar a procurar respostas. Sem uma teoria para definir condiçóes e derivar proposiçốes, os dados são apenas dados. Não se podem encontrar padróes nem explicaçóes sem se basear na teoria. A TER e, mais precisamente, os modelos de escolha racional fornecem a estrutura e os limites das explicaçôes. É aí que a oportunidade da TER reside.

\section{Referências}

ALEXANDROVNA, A.; NORTHCOTT, R. It's just a feeling: why economic models do not explain. Journal of Economic Methodology, Abingdon, v. 20, n. 3, p. 262-267, 2013.

AXELROD, R. The evolution of cooperation. New York: Basic Books, 1984.

The complexity of cooperation: agent-based models of competition and collaboration. Princeton: Princeton University Press, 1997.

BARBERIS, N.; HUANG, M.; THALER, R. Individual preferences, monetary gambles and the equity premium. American Economic Review, Nashville, v. 96, n. 4, p. 1069-1090, 2006.

BAS, M. A.; SIGNORINO, C. S.; WALKER, R. W. Statistical Backward Induction: a simple method for estimating recursive strategic models. Political Analysis, Oxford, v. 16, n. 1, p. 21-40, 2008.

BATES, R. H. et al. Analytic narratives. New Jersey: Princeton University Press, 1998.

BECKER, G. S. The economic approach to human behavior. Chicago: Chicago University Press, 1976.

BENARTZI, S.; THALER, R. H. Myopic loss aversion and the equity premium puzzle. The Quarterly Journal of Economics, Cambridge, v. 110, n. 1, p. 51-71, 1995.

CARTWRIGHT, N. Models: parables v fables. In: FRIGG, R.; HUNTER, M. (Eds.). Beyond mimesis and convention: representation in art and science. Amsterdam: Springer Netherlands, 2010. p. 19-31.

CLARK, W. R.; GOLDER, M. Big data, causal inference, and formal theory: contradictory trends in political science? Introduction. Political Science \& Politics, New York, v. 48, n. 1, p. 65-70, 2015.

CLARKE, K. A.; SIGNORINO, C. S. Discriminating methods: tests for non-nested discrete choice models. Political Studies, Hoboken, v. 58, n. 2, p. 368-388, 2010.

COX, G. The empirical content of rational choice theory: a reply to Green and Shapiro. Journal of Theoretical Politics, Thousand Oaks, v. 11, n. 2, p. 147-169, 1999. 
. Lies, damned lies, and rational choice analyses. In: SHAPIRO, I.; SMITH, R.; MASOUD, T. E. (Eds.). Problems and methods in the study of politics. Cambridge: Cambridge University Press, 2004. p. 167-185.

DOWDING, K. Is it rational to vote? Five types of answer and a suggestion. British Journal of Politics \& International Relations, Hoboken, v. 7, n. 3, p. 442-459, 2005.

Power, luck, and freedom. Manchester: Manchester University Press, 2017.

DOWDING, K.; HINDMOOR, A. The usual suspects: rational choice, socialism and political theory. New Political Economy, Abingdon, v. 2, n. 3, p. 451-463, 1997.

ERIKSSON, L. Rational choice theory: potential and limits. London: Palgrave Macmillan, 2011.

FEHR, E.; FISCHBACHER, U. Why social preferences matter - the impact of non-selfish motives on competition, cooperation and motives. The Economic Journal, Hoboken, v. 112, n. 478, p. C1-C33, 2002.

FIORINA, M. Rational choice, empirical contributions, and the scientific enterprise. Critical Review: A Journal of Politics and Society, Abingdon, v. 9, n. 1-2, p. 85-94, 1995.

FLYVBJERG, B. A Perestroikan straw man answers back: David Laitin and phronetic political science. In: SCHRAM, S.; CATERINO, B. (Eds.). Making political science matter: debating knowledge, research, and method. New York: New York University Press, 2006. p. 56-85.

GIGERENZER, G.; SELTEN, R. Rethinking rationality. In: GIGERENZER, G.; SELTEN, R. (Eds.). Bounded rationality: the adaptive toolbox. Cambridge: The MIT Press, 2001. p. 1-12.

GINTIS, H. Beyond Homo economicus: evidence from experimental economics. Ecological Economics, Amsterdam, v. 35, n. 3, p. 311-322, 2000.

GINTIS, H.; HELBING, D. Homo socialis: an analytical core for sociological theory. Review of Behavioural Economics, Delft, v. 2, n. 1-2, p. 1-59, 2015.

GLIMCHER, P. W. Foundations of neuroeconomic analysis. Oxford: Oxford University Press, 2001.

GREEN, D.; SHAPIRO, I. Pathologies of rational choice theory. New Haven: Yale University Press, 1994.

HAUSMAN, D. M. 'Testing' game theory. Journal of Economic Methodology, Abingdon, v. 12, n. 2, p. 211-223, 2005. Paradox postponed. Journal of Economic Methodology, Abingdon, v. 20, n. 3, p. 250-254, 2013.

HINDMOOR, A. Ian Shapiro and Donald P. Green, Pathologies of rational choice theory: a critique of applications in political science. Utilitas, New York, v. 10, n. 3, p. 370-372, 1998.

HINDMOOR, A.; TAYLOR, B. Rational choice. London: Palgrave Macmillan, 2015. 
HOCHSCHILD, J. L. Editor's note: introduction and observations. Perspectives on Politics, Washington, DC, v. 1, n. 1, p. 1-4, 2003.

HODGSON, G. M. On the limits of rational choice theory. Economic Thought, Bristol, v. 1, n. 1, p. 94-108, 2012.

ISAAC, J. C. From the editor. Perspectives on Politics, Washington DC, v. 13, n. 4, p. 929-934, 2015.

ISHIYAMA, J. Report of the editors of the American Political Science Review, 2013-14. Political Science \& Politics, New York, v. 48, n. 2, p. 400-403, 2015.

JACKSON, P. T. A statistician strikes out: in defense of genuine methodological diversity. In: SCHRAM, S.; CATERINO, B. (Eds.). Making political science matter: debating knowledge, research, and method. New York: New York University Press, 2006. p. 86-97.

JACOBY, W. G. et al. Report to the Editorial Board and the Midwest Political Science Association Executive Council. American Journal of Political Science, Washington, DC, 2017. Disponível em: <https://bit.ly/2HRHUKq >. Acesso em: 13 maio 2018.

JOHNSON, J. Models among the political theorists. American Journal of Political Science, Washington, DC, v. 58, n. 3, p. 547-560, 2014.

Models-as-fables: an alternative to "the standard rationale" for using formal models in political science. In: Midwest Political Science Association Annual Conference, 2017, Chicago. Roundtable: New directions in formal theory. Disponível em: <https://bit.ly/2HOWGBJ>. Acesso em: 14 jun. 2018.

KAHNEMAN, D.; TVERSKY, A. Choices, values, and frames. Cambridge: Cambridge University Press, 2000.

LIMA, E. L. N. B. O. Explanation as prediction: the raison d'être of formal models in Political Science. Revista Politica Hoje, Recife, 2018. No prelo.

LIMA, E. L. N. B. O.; MÖRSCHBÄCHER, M. Contribuiçôes e desafios do institucionalismo histórico na ciência política contemporânea. BIB - Revista Brasileira de Informaçâao Bibliográfica em Ciências Sociais, São Paulo, v. 81, n. 1, p. 103-122, 2017.

LOHMANN, S. The poverty of Green and Shapiro. Critical Review: A Journal of Politics and Society, Abingdon, v. 9, n. 1-2, p. 127-154, 1995.

MÄKI, U. On a paradox of truth, or how not to obscure the issue whether explanatory models can be true. Journal of Economic Methodology, Abingdon, v. 20, n. 3, p. 268-279, 2013.

MONROE, B. L. et al. No! Formal theory, causal inference, and big data are not contradictory trends in political science. Political Science \& Politics, New York, v. 48, n. 1, p. 71-74, 2015.

MORTON, R. M. Methods and models: a guide to the empirical analysis of formal models in political science. Cambridge: Cambridge University Press, 1999. 
Norris, P. Towards a more cosmopolitan political science? European Journal of Political Research, Hoboken, v. 31, n. 1, p. 17-34, 1997.

QUACKENBUSH, S. The rationality of rational choice theory. International Interactions, Abingdon, v. 30, n. 2, p. $87-107,2004$.

REISS, J. The explanation paradox redux. Journal of Economic Methodology, Abingdon, v. 20, n. 3, p. 280-292, 2013.

ROSENKRANZ, S.; SCHMITZ, P. W. Reserve prices in auctions as reference points. The Economic Journal, Hoboken, v. 117, n. 520, p. 637-653, 2007.

RUBINSTEIN, A. Comments on the interpretation of game theory. Econometrica, New York, v. 59, n. 4, p. 909-924, 1991.

SATZ, D.; FEREJOHN, J. Rational choice and social theory. Journal of Philosophy, New York, v. 91, n. 2, p. 71-87, 1994.

SCHEIBEHENNE, B.; RIESKAMP, J.; WAGENMAKERS, E.-J. Testing adaptive toolbox models: a Bayesian hierarchical approach. Psychological Review, Washington, DC, v. 120, n. 1, p. 39-64, 2013.

SCHRAM, S.; CATERINO, B. Introduction: reframing the debate. In: SCHRAM, S.; CATERINO, B. (Eds.). Making political science matter: debating knowledge, research, and method. New York: New York University Press, 2006. p. 1-16.

SCHWARTZ-SHEA, P. Conundrums in the practice of pluralism. In: SCHRAM, S.; CATERINO, B. (Eds.). Making political science matter: debating knowledge, research, and method. New York: New York University Press, 2006. p. 209-221.

SELTEN, R. What is bounded rationality? In: GIGERENZER, G.; SELTEN, R. (Eds.). Bounded rationality: the adaptive toolbox. Cambridge: The MIT Press, 2001. p. 13-36.

SEN, A. The formulation of rational choice. The American Economic Review, Nashville, v. 84, n. 2, p. 385-390, 1994. Maximization and the act of choice. Econometrica, New York, v. 65, n. 4, p. 745-779, 1997. A ideia de justiça. São Paulo: Companhia das Letras, 2009.

SHAPIRO, I.; SMITH, R.; MASOUD, T. Introduction: problems and methods in the study of politics In: SHAPIRO, I.; SMITH, R.; MASOUD, T. (Eds.). Problems and methods in the study of politics. Cambridge: Cambridge University Press, 2004. p. 1-18.

SIGNORINO, C. S.; YILMAZ, K. Strategic misspecification in regression models. American Journal of Political Science, Washington, DC, v. 47, n. 3, p. 551-566, 2003.

SIGNORINO, C. S. On formal theory and statistical methods: a response to Carrubba, Yuen and Zorn. Political Analysis, Oxford, v. 15, n. 4, p. 483-501, 2007.

SIMON, H. A. Models of man. New York: Wiley, 1957. 
SLOVIC, P. The construction of preference. In: KAHNEMAN, D.; TVERSKY, A. (Eds.). Choices, values, and frames. Cambridge: Cambridge University Press, 2000.

SNIDAL, D. Rational choice and international relations. In: CARLSNAES, W.; RISSE, T.; SIMMONS, B. A. (Eds.). Handbook of International Relations. London: SAGE, 2006. p. 73-94.

SUGDEN, R. Explanations in search of observations. Biology and Philosophy, New York, v. 26, n. 5, p. 717-736, 2011. How fictional accounts can explain. Journal of Economic Methodology, Abingdon, v. 20, n. 3, p. 237-243, 2013.

THELEN, K. Historical institutionalism in comparative politics. Annual Review of Political Science, Palo Alto, v. 2, n. 1, p. 369-404, 1999.

THELEN, K.; MAHONEY, J. Comparative-historical analyses in contemporary political science. In: MAHONEY, J.; THELEN, K. (Eds.). Advances in comparative-historical analysis. Cambridge: Cambridge University Press, 2015. p. 3-36.

VON NEUMANN, J.; MORGENSTERN, O. Theory of games and economic behaviour. Princeton, Princeton University Press, 2007.

\section{Resumo}

Críticas à teoria da escolha racional e hierarquias de conhecimento na ciência politica

A teoria da escolha racional tornou-se anátema na ciência política contemporânea. Desde os primeiros modelos de escolha racional, os teóricos dessa linha são criticados pelo conteúdo epistemológico de seus trabalhos, bem como pelo recurso a modelos formais como abordagem metodológica dos fenômenos políticos. As críticas reverberam em diferentes disciplinas, nomeadamente psicologia, economia e ciência política. Este artigo reconstrói os debates na área de ciências comportamentais e cognitivas, e na própria disciplina de ciência política, buscando compreender como eles se desenvolveram. O artigo também apresenta dados bibliométricos sobre a produção recente em teoria da escolha racional e discute como eles revelam hierarquias do conhecimento sobre a alegada proeminência de modelos de escolha racional nos principais periódicos de ciência política.

Palavras-chave: Teoria da Escolha Racional; Modelos Formais; Hierarquias do Conhecimento.

\section{Abstract}

\section{Critiques of rational choice theory and hierarchies of knowledge in political science}

The rational choice theory has become an anathema in contemporary political science. Ever since the first models of rational choice were created, theorists of this line are criticized by the epistemological content of their studies, as well as by the use of formal models as the methodological approach of political phenomena. The criticism occurs in different disciplines, namely psychology, economics and political science. This article reconstructs the debates that occurred within behavioral and cognitive sciences, as well as in political science itself, seeking to understand how they were developed. This article also presents bibliometric data on the recent production in rational choice theory and discusses how they reveal hierarchies of knowledge about the alleged prominence of rational choice models in the major political science journals.

Keywords: Rational Choice Theory; Formal Models; Hierarchies of knowledge. 


\section{Résumé}

Critique de la théorie du choix rationnel et des hiérarchies des connaissances en sciences politiques

La théorie du choix rationnel est devenue anathème dans la science politique contemporaine. Depuis les premiers modèles de choix rationnel, les théoriciens de cette ligne sont critiqués par le contenu épistémologique de leurs travaux, ainsi que par l'utilisation de modèles formels comme approche méthodologique des phénomènes politiques. Les critiques se répercutent dans différentes disciplines, à savoir la psychologie, l'économie et la science politique. Cet article reconstruit les débats dans le domaine des sciences comportementales et cognitives, et dans la discipline de la science politique elle-même, pour essayer de comprendre comment ils se sont développés. L'article présente aussi des informations bibliométriques de la production récente sur la théorie du choix rationnel, en examinant comment elles révèlent des hiérarchies des connaissances sur la proéminence alléguée des modèles de choix rationnels dans les principaux périodiques de sciences politiques.

Mots clés: Théorie du choix rationnel; Modèles formels; Hiérarchies des Connaissance. 